American Journal of Pharmaceutical Education 2021; 85 (5) Article 8536.

\title{
COMMENTARY
}

\section{True Entrustment Decisions Regarding Entrustable Professional Activities Happen in the Workplace, not in the Classroom Setting}

\author{
Adam M. Persky, PhD, ${ }^{\mathrm{a}, \mathrm{b}}$ Kathryn A. Fuller, PharmD, ${ }^{\mathrm{a}}$ Olle ten Cate ${ }^{\mathrm{c}}$ \\ ${ }^{a}$ University of North Carolina at Chapel Hill, UNC Eshelman School of Pharmacy, Chapel Hill, North Carolina \\ ${ }^{\mathrm{b}}$ Associate Editor, American Journal of Pharmaceutical Education, Arlington, Virginia \\ ${ }^{\mathrm{c}}$ Center for Research and Development of Education, University Medical Center Utrecht, Utrecht, the Netherlands \\ Submitted January 1, 2021; accepted January 27, 2021; published May 2021.
}

\begin{abstract}
Entrustable Professional Activities (EPAs) are workplace responsibilities that directly impact patient care. The use of EPAs allows pharmacy faculty and preceptors to provide learners with feedback and assessment in the clinical setting. Because they focus assessment on a learner's execution of professional activities which requires integration of the respective competencies, EPAs help provide a more holistic picture of a learner's performance. Using EPAs to backwards design classroom learning for those competencies is highly encouraged, but instructors cannot or should not assess performance and make entrustment decisions using EPAs in the classroom setting for several reasons: a learner's classroom performance usually does not predict clinical performance very well, assessment of EPAs require direct observation of the learner performing the EPAs, EPA assessment requires multiple observations of the learner with different patients with varying level of acuity, and most importantly, EPA assessment must result in a decision to trust the learner to perform the clinical activity with limited supervision. By ensuring all entrustment decisions are made in a clinical or experiential setting, students will receive an accurate assessment and benchmark of their performance that will lead them one step closer to becoming independent practitioners.
\end{abstract}

Keywords: entrustable professional activities, EPA, assessment, experiential, didactic

\section{INTRODUCTION}

An increasing number of Doctor of Pharmacy (PharmD) programs are using Entrustable Professional Activities for programmatic assessment. Entrustable Professional Activities (EPAs) are workplace tasks or responsibilities that clinicians trust a trainee (eg, student pharmacist) to execute unsupervised once he or she has obtained an adequate level of competence. ${ }^{1}$ As such, EPAs have the following characteristics: they are executable within a given timeframe (eg, over the course of a residency), they are general enough to be flexible across different clinical practice settings (eg, perform procedures and implement therapies inpatient and outpatient), and they are observable and measurable and therefore suited for use in making entrustment decisions. The difference between an EPA and a more traditional learning objective or competency based outcome is that EPAs are units of work and a method to translate competencies to clinical practice, while competencies themselves are

Corresponding Author: Adam M. Persky, University of North Carolina at Chapel Hill, UNC Eshelman School of Pharmacy, 325 Beard Hall, CB\#7569, Chapel Hill, NC 27599. Tel: 919-966-9104. Email: apersky@unc.edu related to a learner ability. ${ }^{2}$ Typically, competencies are described as features that include knowledge, professional attitude, communication skill, collaboration skill, etc (Figure 1, Table 1). In essence, EPAs are future objectives as they require a practitioner to integrate multiple competencies from several varying domains, including: content expertise, collaboration, communication, and management. ${ }^{3}$ Conversely, each competency is relevant to many different EPAs (Figure 1). To be assessed, EPAs require observation of a learner's global performance in units of professional practice in an authentic clinical setting. ${ }^{4,5}$ Assuming EPAs can be performed in a classroom setting neglects the idea that the activities are contributions to health care. ${ }^{6}$ Thus, entrustment decisions for EPAs can only be made while observing the learner engaged in the provision of health care in a professional practice setting. ${ }^{7-9}$

\section{DISCUSSION}

Even though EPAs were intended to be used to determine entrustment in an authentic practice setting, it does not necessarily follow that EPAs are irrelevant for classroom education. ${ }^{6,10}$ Any curriculum designed to prepare student pharmacists for practice can be taught in 


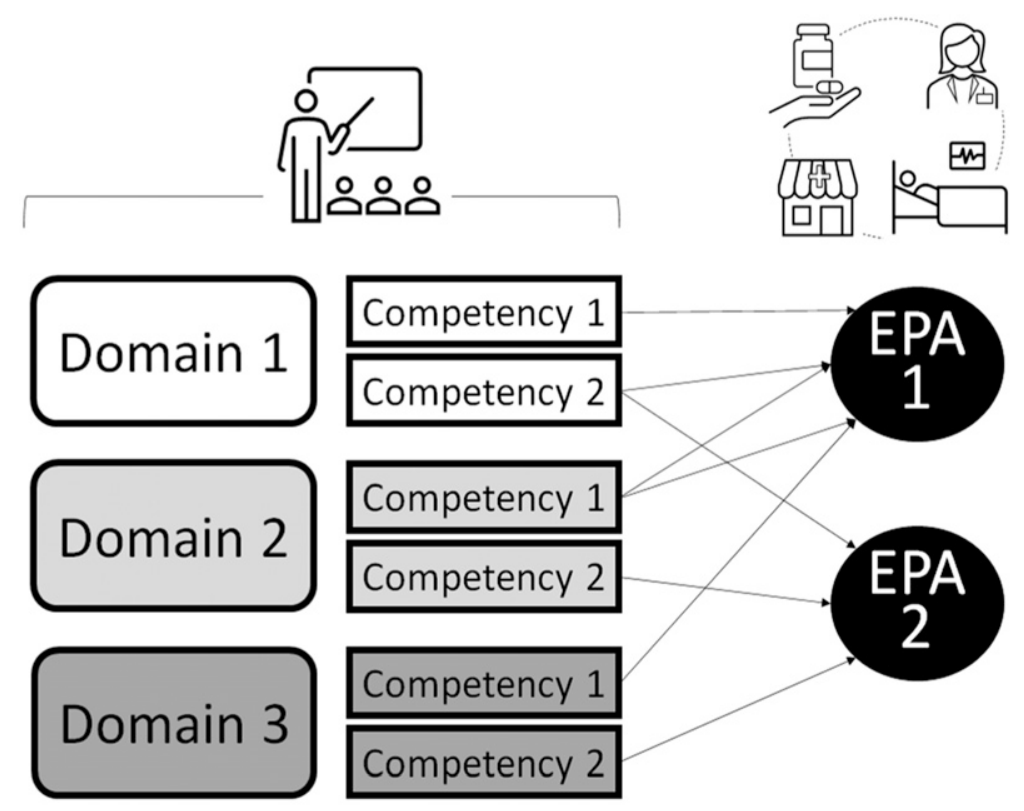

\section{Competency/Learning Objective}

$\begin{array}{ll}\text { Context } & \text { Classroom } \\ \text { Represents } & \begin{array}{l}\text { Granular definitions of what is } \\ \text { good pharmacist }\end{array} \\ \text { Assessment } & \begin{array}{l}\text { Traditional (exams, etc) } \\ \text { History }\end{array} \\ \begin{array}{l}\text { Long history of how we think } \\ \text { about learners }\end{array}\end{array}$

\section{EPA}

Workplace

Day to day work

Supervision of activities

New and intended for residency-to-practice transition

Figure 1. Comparison of Entrustable Professional Activities (EPAs) and Learning Objectives ${ }^{5}$

the didactic setting before students assume actual patient care responsibilities on clinical rotations. Each EPA requires that a learner have specific competencies in knowledge, skills, attitudes, and experiences before they can be entrusted with a clinical task. While classroom instruction is necessary for learners to acquire the foundational knowledge, skills, and attitudes needed to achieve many of these competencies, didactic learning alone is not sufficient. Using a backwards design approach, course instructors of "pre-experiential" courses can use EPAs to inform which competencies should be developed in learners in the classroom setting and are necessary prior to learners beginning experiential learning. Therefore, the classroom setting is the perfect environment for aligning competencies with the future EPAs of experiential and clinical learning where true entrustment decisions can be made. As such, instructors of didactic courses, whether the course content is foundational science, clinical, or social administrative, should be aware of EPAs and how to ensure alignment of EPAs with the didactic curriculum in the resurgence of competency-based learning. ${ }^{2,11,12}$

While faculty want to thoroughly prepare students in the classroom for their experiential pharmacy education, it is important to do so using accurate and evidencedbased didactic methods of teaching and assessment. Assessing students on EPAs and making entrustment decisions in the didactic setting would be faulty and meaningless. Allowing a student to work without supervision before they have even entered the clinical arena would be inappropriate. Additionally, student performance in the classroom does not necessarily predict clinical performance. ${ }^{13}$ A student might appear to be 
American Journal of Pharmaceutical Education 2021; 85 (5) Article 8536.

Table 1. Summary of Assessment of Entrustable Professional Activities in Student Pharmacists in an Experiential Environment vs a Classroom Environment ${ }^{17}$

\begin{tabular}{|c|c|c|c|}
\hline $\begin{array}{l}\text { Entrustment } \\
\text { Decisions Based on... }\end{array}$ & $\begin{array}{l}\text { Abbie (Experiential } \\
\text { Environment) }\end{array}$ & $\begin{array}{l}\text { Billy (Classroom } \\
\text { Environment) }\end{array}$ & Explanation \\
\hline Direct observation & Yes & No & $\begin{array}{l}\text { A preceptor can observe the process of Abbie } \\
\text { interacting with the patient and treatment } \\
\text { team with subsequent assessment of written } \\
\text { or verbal recommendation. However, in the } \\
\text { classroom, Billy will not be observed while } \\
\text { he completes his pharmacotherapy consult } \\
\text { note over the course of a week and he may } \\
\text { have done so with additional help or } \\
\text { resources. }\end{array}$ \\
\hline $\begin{array}{l}\text { Observed in multiple } \\
\text { clinical settings }\end{array}$ & Yes & No & $\begin{array}{l}\text { Abbie completed her Advanced Pharmacy } \\
\text { Practice Experiences in a variety of settings } \\
\text { including the intensive care unit and } \\
\text { ambulatory care clinic and therefore was able } \\
\text { to be observed in multiple settings. However, } \\
\text { Billy was only observed in the classroom } \\
\text { setting while completing case notes around } \\
\text { different pharmacotherapy topics }\end{array}$ \\
\hline $\begin{array}{l}\text { Varying context, acuity, } \\
\text { complexity and varying } \\
\text { patient characteristics }\end{array}$ & Yes & Maybe & $\begin{array}{l}\text { During her Internal Medicine rotation, Abbie } \\
\text { worked with multiple patients of different } \\
\text { complexities and acuities and subsequently } \\
\text { modified her treatment plans based on } \\
\text { varying patient characteristics. However, } \\
\text { Billy read about one patient characteristic } \\
\text { with one level of acuity which lacked varying } \\
\text { context. }\end{array}$ \\
\hline Independence/Unsupervised & Yes & No & $\begin{array}{l}\text { During rotations Abbie can demonstrate } \\
\text { independence in the experiential setting as } \\
\text { she is able to be left alone while she educates } \\
\text { a patient or provides a recommendation to the } \\
\text { treatment team. However, Billy cannot } \\
\text { demonstrate independence as there was no } \\
\text { direct observation confirming the level of } \\
\text { entrustment and it is unknown what resources } \\
\text { were used to make his clinical decision. }\end{array}$ \\
\hline
\end{tabular}

"competent" in a classroom setting where timelines and available resources are more favorable, but exhibit "dependence" or poor performance in the experiential setting. Most clinical preceptors can provide examples of learners who perform well on written examinations and simulated tests of clinical skills, but are far below "competent" in experiential performance. ${ }^{1}$ To be trusted to work in the clinical setting without supervision, studies show that the learner must exhibit both task-specific competency and general professional qualities ${ }^{4}$ These general qualities include agency, reliability, integrity, humility, and capability. ${ }^{4}$

Let us examine an extreme example involving a $\mathrm{PhD}$-trained pharmacokineticist with 20 years of experience in research and teaching in the discipline. Despite his long history in academia, extensive drug knowledge, and ability to perform dosing calculations expertly, he cannot (or should not) be entrusted with properly dosing a medication for an actual patient in a clinical practice setting. This example illustrates the difference between didactic and experiential learning and knowledge and why examination of a learner's ability to execute clinical tasks should be done in a clinical environment and not in a didactic setting. Making entrustment decisions differs from conducting a standard assessment of a leaner as a standard assessment in the classroom does not have the direct consequences of patient care and as such serves as a proxy measure rather than an authentic workplace measure. ${ }^{4}$

Because EPAs are solely workplace practices or tasks, there is an additional concern with using EPAs to 


\section{American Journal of Pharmaceutical Education 2021; 85 (5) Article 8536.}

assess learners in the didactic setting. In the classroom, instructors attempt to simulate the workplace or experiential environment by using patient cases, simulated electronic health records, or even standardized patients. However, hypothetical cases do not involve the learner engaging in authentic workplace activities with real patients and therefore do not fit within the EPA philosophy. In order for EPAs to be correctly and accurately assessed they must reflect the learner making an actual contribution to health care. ${ }^{6}$ One may argue that assessment using standardized patients or objective structured clinical examinations (OSCEs) is closer to experiences in experiential learning than classroom learning and therefore could be used to assess a learner's readiness for EPAs. However, these simulated environments are still not sufficient to use for EPA assessment unless the required skill is rare. For example, a basic life support class can prepare a student to perform the clinical tasks required for administering emergency care when needed. In this case, entrustment in the learner's ability to perform these tasks can be assessed in a simulated environment as actual emergency clinical situations are rare and attempting to teach the student within an authentic environment (eg, hospital emergency department) might place a patient at greater risk. A simulated environment may be the only setting in which assessment of an EPA, eg, a student's ability to resuscitate a patient, can be conducted and which otherwise might not be able to be assessed. In contrast, using a simulated environment or written patient cases to provide student entrustment around counseling patients, provide recommendations or determining a pharmacotherapy assessment and plan would not be appropriate as these are all clinical tasks that can be well observed and assessed repeatedly in the live experiential setting.

Finally, in the classroom setting, learners are tasked with reading about one patient case at a time with static context, acuity, and complexity and providing an assessment and plan for this patient. As a result, entrustment decisions cannot be made in the classroom setting. Entrustment decisions should instead be made after EPAs have been observed multiple times in multiple settings and with a variety of patients with different characteristics, disease complexity, acuity and severity.$^{3}$ To further explain the implications of making entrustment decisions about student pharmacists in non-clinical environments consider the following scenarios.

Abbie is a fourth-year student pharmacist who recently completed her general medicine experience. During the rotation, she was responsible for the assessment and management of four to eight patients a day. Over the course of the month, the preceptor directly observed
Abbie providing appropriate medication counseling to patients, providing appropriate treatment interventions to the team, and appropriately documenting a variety of clinical encounters. For each of the above observations, Abbie provided accurate, patient-centered, and evidencebased information without unnecessary details or repetition. She was able to accurately interpret laboratory values and key problems while communicating bidirectionally with other professionals to develop the plan. Abbie's documentation and tasks were completed in a timely fashion and contained the required elements of the practice site. The clinical documentation that Abbie provided to her preceptor contained the problem list and treatment plan and reflected a combination of critical thinking processes.

Billy is a third-year student pharmacist who recently completed the pharmacotherapy course. Within the course, Billy was required to provide pharmacotherapy management for approximately one patient a week. To do so, he completed an online patient encounter that consisted of using a simulated electronic health record of a patient in a general medicine practice. Using this information, Billy was expected to provide patient counseling points and appropriate treatment recommendations for the patient and to document all relevant information over a week's time. During the week, and under no direct observation, Billy interacted with classmates and the instructor to help decipher the patient case and determine the appropriate recommendations and had unlimited access to online resources. For the clinical case, Billy provided accurate, patient-centered, evidence-based information that did not contain unnecessary details or repetitions. He was able to accurately interpret laboratory values and key problems while communicating bidirectionally to develop the plan. His documentation and tasks were completed in a timely fashion and contained the required elements of the practice site. The clinical documentation provided contained the problem list and plan and reflected a combination of critical thinking processes.

Clearly, in one of the two scenarios, the student pharmacist worked within the necessary environment for EPA assessment to be conducted while the other did not as EPAs are more than the ability to complete a clinical task. The activity observed must demonstrate the student's ability to make a contribution to healthcare. ${ }^{6}$ As shown in Table 1, in the experiential setting, faculty have the opportunity to directly observe the student pharmacist performing clinical tasks and could assess the degree to which the student could be trusted with performing various activities in varying contexts. However, in the classroom, faculty could only observe the student pharmacist indirectly, with a minimal variety of patient 


\section{American Journal of Pharmaceutical Education 2021; 85 (5) Article 8536.}

situations, especially while the student is completing a task considered to be an EPA. Additionally, the student in the experiential setting interacted with many patients daily with diseases of varying complexity and acuity while the student in the classroom was allowed to focus on one patient with much less complexity or acuity. While it could be argued that these classroom activities are simulations, the evidence is clear regarding the role of simulated assessments in that these are saved for impractical or rare clinical experiences such as described before about emergency resuscitation.

Ultimately, when making an entrustment decision, the supervising clinician is putting their license on the line when they state that a student is ready for unsupervised pharmacy practice and there is no way this decision could (or should) occur in a pure classroom setting. The decision to endorse the highest level of student ability happens after repeated daily observation of a student in the practice setting. This repeated observation is what allows the supervising clinician to feel as though they can confidently leave the learner in the practice site under supervision without putting patients or other practitioners at risk. ${ }^{14,15}$ While there are varying scales for clinical supervisors to use in determining how much help or supervision a student needs to adequately perform a specific activity, none of them involve providing this entrustment decision in the classroom. ${ }^{16}$

\section{CONCLUSION}

Entrustable professional activities are contributions to health care and entrustment decisions are made by practitioners to allow learners to start making these contributions with varying levels of supervision. Therefore, the decision to entrust a learner with performing an EPA should only be made in a clinical setting after multiple observations. As a result, there are only a few exceptions to the rule that entrustment decisions should only be made in a live clinical setting. However, a decision that the learner is ready for indirect supervision to execute will rarely happen outside the workplace.

The use of EPAs allows learners to be provided with feedback and assessment in the workplace or clinical setting. Entrustable professional activities also provide a more holistic picture of student performance. While using EPAs to backwards design classroom competencies is highly encouraged, a faculty should not attempt to assess a student's performance using EPAs in the classroom setting because classroom performance does not predict clinical performance, assessment of EPAs requires direct observations, and accurate assessment of EPAs requires multiple observations with a variety of patients with varying levels of acuity. By ensuring that all entrustment decisions are made in a clinical or experiential setting, student pharmacists will receive an accurate assessment and benchmark of their performance that will lead them one step closer to becoming independent practitioners. Decisions to entrust a learner with critical health care activities must lead to an increase of responsibilities and autonomy, or otherwise such decisions are empty and will loose the significance of the expression of entrustment.

\section{REFERENCES}

1. El-Haddad C, Damodaran A, McNeil HP, Hu W. The ABCs of entrustable professional activities: an overview of 'entrustable professional activities' in medical education. Internal Med J. 2016; 46(9):1006-1610.

2. ten Cate O. AM Last Page: what entrustable professional activities add to a competency-based curriculum. Acad Med. 2014;89(4):691.

3 . ten Cate O. Nuts and bolts of entrustable professional activities. $J$ Grad Med Educ. 2013;5(1):157-158.

4. ten Cate O, Chen HC. The ingredients of a rich entrustment decision. Med Teach. 2020;42(12):1413-1420.

5. Obeso V, Brown D, Aiyer M, et al. Core EPAs for Entering Residency Pilot Program. Toolkits for the 13 Core Entrustable Professional Activities for Entering Residency. Washington, DC: Association of American Medical Colleges; 2017.

6. ten Cate O, Taylor DR. The recommended description of an entrustable professional activity: AMEE Guide No. 140. Med Teach. 2020;1-9.

7. ten Cate O. Entrustment as assessment: recognizing the ability, the right, and the duty to act. J Grad Med Educ. 2016;8(2):261-262. 8. ten Cate O. Entrustment decisions: bringing the patient into the assessment equation. Acad Med. 2017;92(6):736-738.

9. ten Cate O, Hart D, Ankel F, et al. Entrustment decision making in clinical training. Acad Med. 2016;91(2):191-198.

10. Kanmaz TJ, Culhane NS, Berenbrok LA, et al. Curriculum crosswalk of the core entrustable professional activities for new pharmacy graduates. Am J Pharm Educ. 2020;84(11):8077.

11. Frank J, Snell L, Sherbino J. CanMEDS 2015 Physician Competency Framework: Ottawa: Royal College of Physicians and Surgeons of Canada; 2015.

12. Frank JR, Snell LS, ten Cate O, et al. Competency-based medical education: theory to practice. Med Teach. 2010;32(8):638-645.

13. Page GG, Fielding DW. Performance on pmps and performance in practice: are they related? Acad Med. 1980;55(6):529-537.

14. Chen HC, Teherani A. Workplace affordances to increase learner engagement in the clinical workplace. Med Educ. 2015;49(12): 1184-1186.

15. ten Cate O, Chen HC. The ingredients of a rich entrustment decision. Med Teach. 2020; 42(12):1413-1420

16. Rekman J, Gofton W, Dudek N, Gofton T, Hamstra SJ. Entrustability scales: outlining their usefulness for competency-based clinical assessment. Acad Med. 2016;91(2): 186-190.

17. ten Cate O, Chen HC, Hoff RG, Peters H, Bok H, van der Schaaf M. Curriculum development for the workplace using entrustable professional activities (EPAs): AMEE Guide No. 99. Med Teach. 2015;37(11):983-1002. 